Research Article

\title{
Driving Comfort Evaluation for Manhole Covers and Pavement around Manholes
}

\author{
Quanman Zhao $\mathbb{D}^{1}{ }^{1}$ Zhigang Li $\left(\mathbb{D},{ }^{1}\right.$ Wenjun $\mathrm{Hu}^{1},{ }^{1}$ Xianguang Meng, ${ }^{2}$ and Hui Zhang ${ }^{1}$ \\ ${ }^{1}$ School of Transportation Engineering, Shandong Jianzhu University, Jinan 250101, China \\ ${ }^{2}$ Jinan Municipal Engineering Design \& Research Institute (Group) Co. Ltd., Jinan 250101, China
}

Correspondence should be addressed to Zhigang Li; lizhigang@chd.edu.cn

Received 22 June 2019; Accepted 11 September 2019; Published 3 October 2019

Academic Editor: Francesco Ruffino

Copyright (C) 2019 Quanman Zhao et al. This is an open access article distributed under the Creative Commons Attribution License, which permits unrestricted use, distribution, and reproduction in any medium, provided the original work is properly cited.

\begin{abstract}
In order to study the driving comfort and influencing factors when vehicles pass over manholes and pavement around manholes on an urban road, the deformation and vibration of the manhole cover were considered, a multidegree of freedom vibration model of the human-vehicle-manhole cover was established, and the variation characteristics of driving acceleration was analyzed. The root mean square of weighted acceleration was taken as the basic index, and driving comfort was evaluated based on ISO 2631-11997 standard. After that, 9 influencing factors were analyzed, such as driving speed, subsidence of manhole, manhole cover stiffness, and longitudinal slope. Then, grey correlation entropy analysis was used to evaluate the influencing factors, and the main factors were determined. The results showed that the maximum acceleration was $3.6 \mathrm{~m} / \mathrm{s}^{2}$ when a vehicle was passing over a manhole cover under the basic parameters. At the same time, the root mean square of weighted acceleration was $0.975 \mathrm{~m} / \mathrm{s}^{2}$ and driving comfort degree was "uncomfortable." Driving direction and vibration of the manhole cover had little influence on driving comfort, while the remaining influencing factors had significant influence on that. The ranking of key influence factors on driving comfort was longitudinal slope, driving speed, height difference caused by pavement damage, height difference caused by manhole cover subsidence, tire stiffness, manhole stiffness, and tire damping. Therefore, in order to ensure driving comfort and safety, damage to pavement around manholes and manhole cover subsidence should be repaired in a timely manner.
\end{abstract}

\section{Introduction}

Urban pipeline networks are an important part of municipal facilities, known as the "arteries of the city," and manholes are indispensable components of urban pipeline networks, playing an important role in installation, inspection, and maintenance processes. Due to the difference of stiffness and structure, these areas are weak points in the pavement. Investigations have found that more than $90 \%$ of manholes in China have damage, which can be divided into subsidence in manhole, cracking in pavement around the manhole, cover fracture, and subsidence in pavement around the manhole [1].

Existing research on manholes and pavement around manholes (referring to the pavement in a certain range around manholes) mainly focuses on the settlement mechanism of manholes, design of new manhole structures, development mechanism of damage in pavement around manholes, and the repair materials for damage in pavement around manholes. A longitudinal vibration equation of manholes under traffic loads was constructed [2], and the settlement mechanism of manholes was studied. Materials were chosen and optimized according to corrosion resistance, fatigue resistance, and impact resistance based on many physical and mechanical property tests [3]. And three kinds of manhole cover were developed, including toughened organic glass manhole cover, toughened inorganic glass manhole cover, and toughened organic/inorganic composite glass manhole cover. A new type of epoxy resin-modified concrete manhole structure which was of good mechanical properties was developed [4]. A manhole and pavement around manhole model were established, then tensile, 
compressive, and shear stress of pavement around manholes under static loads were calculated, which revealed the failure mechanism of pavement around manholes, and reasonable suggestions for improved design and construction of manhole structures were put forward [5]. In terms of pavement repair materials, high-performance cement repair materials [6], resin cement [7], cold-filled asphalt mixtures [8], polyurethane rubber particle mixtures [9], etc., were developed and used in physical engineering, showing good performance.

However, there is currently little research on the comfort and safety of vehicles passing over manholes. When damage to manholes and pavement around manholes occurs, driving comfort can be seriously affected, and serious traffic accidents can occur. A vehicle vibration model and roughness model were constructed to analyze the dynamic load characteristics of vehicles by different simplifying vehicle models [10-17]. The research proved that a $1 / 4$ vehicle vibration model could meet the accuracy requirements of most research $[18,19]$. Although all directions of vehicle vibration were considered, this model was complicated and difficult to solve. In addition, the introduction of more parameters brought a lot of interference to the research and reduced the research efficiency.

At present, there are many studies on driving comfort. Based on MATLAB/Simulink simulation analysis, a 1/4 vehicle vibration model and a comprehensive evaluation method of airport and highway pavement roughness were proposed $[18,20]$. A $1 / 2$ vehicle vibration model was established which was used to analyze the interaction between vehicle and pavement [21]. After that the development law of vehicle dynamic load with road grade and speed was proposed. Considering the vehicle and road coupling effect, the human-vehicle-road-coupled vibration model was established [22], and an evaluation method of pavement roughness was proposed. A 1/4 vehicle vibration model was constructed [19], and the mechanism of pavement roughness deterioration was studied based on the theory of shell permanent deformation.

When the vehicle passed over a manhole, the vehicle vibration characteristics and driving comfort were obviously different from those when passing over a normal section of road. While the vehicle passed over the pavement around a manhole and a normal section of pavement, deformation (order of magnitude of $0.1 \mathrm{~mm}$ ) and vibration of the pavement were small enough to be ignored. However, when the vehicle passed over the manhole cover, obvious deformation and vibration of the manhole cover occurred, which greatly aggravated the vibration of the vehicle and seriously affected driving comfort. In order to evaluate the driving comfort and find the key influence factors on the driving comfort while vehicle passing through the manhole, a coupled vibration model of a human-vehicle-manhole cover was established considering the deformation and vibration of the manhole cover, and weighted root mean square acceleration was used as the evaluation index of driving comfort. The driving comfort of a vehicle passing over a manhole was evaluated according to ISO 2631-1-1997 standard. Grey correlation entropy analysis was used to analyze the influence of vehicle speed, manhole cover stiffness, longitudinal slope, subsidence of manhole, etc., on driving comfort and to figure out the key influencing factors in order to lay a foundation for the maintenance of the pavement around manholes.

\section{Vibration Model of Human-Vehicle- Manhole Cover}

2.1. Establishment of Model. As a complex system of multiparticle vibration which is generally considered to have 18 degrees of freedom, it is difficult to build a model according to the actual situation. Therefore, it is necessary to simplify the model. At present, the $1 / 2$ vehicle vibration model of 5 DOFs [22] and 1/4 vehicle vibration model of 3 (or 2) DOFs [11] are commonly used simplified models. Moreover, it has been proved that the $1 / 4$ vehicle vibration model is feasible for studying driving comfort [11]. When vehicles pass over the pavement around manholes, the deformation and vibration of the pavement are negligible compared with that of the manhole cover. Therefore, when a vehicle passes over the pavement around manholes, the vibration of the pavement is ignored, and the $1 / 4$ vehicle vibration model of 3 DOFs was established; when a vehicle passes over the manhole cover, the deformation and vibration of the manhole cover are both taken into account, and the 1/4 vehicle vibration model of 4 DOFs (human-vehicle-manhole cover) is shown in Figure 1.

In Figure $1, m_{1}, m_{2}, m_{3}$, and $m_{4}$ are the weights of the vehicle seat, frame, wheel, and manhole cover; $y_{1}, y_{2}, y_{3}$, and $y_{4}$ are the displacements; $k_{1}, k_{2}, k_{3}$, and $k_{4}$ are the stiffness coefficients; $c_{1}, c_{2}, c_{3}$, and $c_{4}$ are the damp coefficients, respectively; $\xi(t)$ is the pavement unevenness; and $v$ is the vehicle speed. As shown in Figure 1, the process of a vehicle passing over a manhole cover and the pavement around manhole is divided into four stages: (1) on pavement around manhole $\longrightarrow(2)$ on manhole cover $\longrightarrow$ (3) on pavement around manhole $\longrightarrow(4)$ on normal pavement. In stage 2 , considering the deformation and vibration of the manhole cover, a 4-DOF vehicle vibration model was established, and a 3 -DOF vehicle vibration model was established in the remaining stages.

It was assumed that the pavement roughness was good except for the degradation of manhole settlement and the pit slot in the pavement around the manhole. Considering the damage as an unevenness incentive in the calculation process, the 3-DOF vibration model was established as follows:

$$
\begin{aligned}
m_{1} \ddot{y}_{1}+k_{1}\left(y_{1}-y_{2}\right)+c_{1}\left(\dot{y}_{1}-\dot{y}_{2}\right) & =0, \\
m_{2} \ddot{y}_{2}+k_{2}\left(y_{2}-y_{3}\right)+c_{2}\left(\dot{y}_{2}-\dot{y}_{3}\right)+k_{1}\left(y_{2}-y_{1}\right)+c_{1}\left(\dot{y}_{2}-\dot{y}_{1}\right) & =0, \\
m_{3} \ddot{y}_{3}+k_{3} y_{3}+c_{3} \dot{y}_{3}+k_{2}\left(y_{3}-y_{2}\right)+c_{2}\left(\dot{y}_{3}-\dot{y}_{2}\right) & =0 .
\end{aligned}
$$

Obvious deformation and vibration of the manhole cover occurred due to the vehicle passing over it, and the human-vehicle-manhole cover 4 -DOF vibration model was established, as shown in the following equation: 


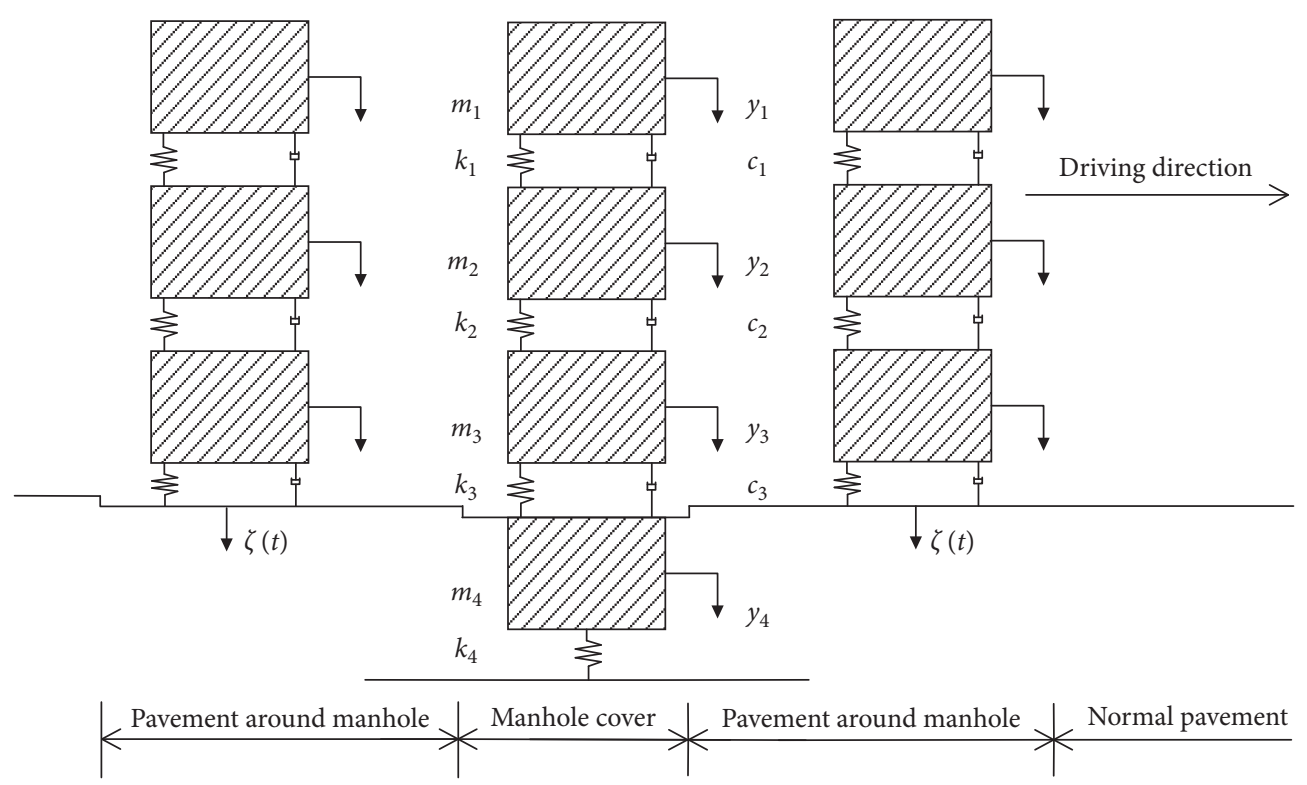

FIGURE 1: Human-vehicle-manhole cover vibration model.

$$
\begin{aligned}
m_{1} \ddot{y}_{1}+k_{1}\left(y_{1}-y_{2}\right)+c_{1}\left(\dot{y}_{1}-\dot{y}_{2}\right) & =0, \\
m_{2} \ddot{y}_{2}+k_{2}\left(y_{2}-y_{3}\right)+c_{2}\left(\dot{y}_{2}-\dot{y}_{3}\right)+k_{1}\left(y_{2}-y_{1}\right)+c_{1}\left(\dot{y}_{2}-\dot{y}_{1}\right) & =0, \\
m_{3} \ddot{y}_{3}+k_{3}\left(y_{3}-y_{4}\right)+c_{3}\left(\dot{y}_{3}-\dot{y}_{4}\right)+k_{2}\left(y_{3}-y_{2}\right)+c_{2}\left(\dot{y}_{3}-\dot{y}_{2}\right) & =0, \\
m_{4} \ddot{y}_{4}+k_{4} y_{4}+k_{3}\left(y_{4}-y_{3}\right)+c_{3}\left(\dot{y}_{4}-\dot{y}_{3}\right) & =0 .
\end{aligned}
$$

The basic parameters of the vehicle and manhole cover model were obtained by accessing relevant references and are shown in Table 1 (the standard axle load is $100 \mathrm{kN}$, so $1 / 4$ vehicle total load is $50 \mathrm{kN}$ ).

2.2. Determination of Initial Conditions. The displacement and velocity parameters were obtained by using the transfer matrix [23] method to solve differential equations (1) and (2). Then the velocity and acceleration parameters were obtained by derivation. Finally, the specific data were obtained by MATLAB. When solving the differential equations, the initial value of vibration was a necessary condition.

\subsubsection{Initial Conditions for Vehicle Passing over Damaged} Pavement around Manhole. When the vehicle passes over the pavement around the manhole from a normal section of pavement, it is assumed that the damage is located at the junction of the two areas. The height difference of the two sections caused by the damage was recorded as $H_{1}$, and the designed longitudinal slope of the pavement was recorded as $\theta$. When the vehicle was stationary on the pavement, the compressions of springs $k_{1}, k_{2}$, and $k_{3}$ of the vehicle vibration model were, respectively, $\Delta k_{1}=m_{1} g / k_{1}$, $\Delta k_{2}=\left(m_{1}+m_{2}\right) g / k_{2}$, and $\Delta k_{3}=\left(m_{1}+m_{2}+m_{3}\right) g / k_{3}$.

(1) Initial Conditions of Velocity. When $H_{1}>\Delta k_{3}$, masses in the vibration model were moving freely. The velocity variation of each mass in the model was neglected for convenience of calculation due to the small drop and short time;
TABLE 1: Parameters for the vehicle and manhole cover.

\begin{tabular}{lc}
\hline Parameters & Value \\
\hline$m_{1}(\mathrm{~kg})$ & 70 \\
$m_{2}(\mathrm{~kg})$ & 4500 \\
$m_{3}(\mathrm{~kg})$ & 430 \\
$m_{4}(\mathrm{~kg})$ & 56 \\
$c_{1}(\mathrm{~N} \cdot \mathrm{s} / \mathrm{m})$ & 1800 \\
$c_{2}(\mathrm{~N} \cdot \mathrm{s} / \mathrm{m})$ & 7000 \\
$k_{1}(\mathrm{~N} / \mathrm{m})$ & 2100 \\
$k_{2}(\mathrm{~N} / \mathrm{m})$ & $9.5 \times 10^{5}$ \\
$k_{3}(\mathrm{~N} / \mathrm{m})$ & $4.8 \times 10^{5}$ \\
$k_{4}(\mathrm{~N} / \mathrm{m})$ & $1 \times 10^{7}$ \\
$c_{3}(\mathrm{~N} \cdot \mathrm{s} / \mathrm{m})$ & 5000 \\
$c_{4}(\mathrm{~N} \cdot \mathrm{s} / \mathrm{m})$ & 0 \\
\hline
\end{tabular}

when $H_{1} \leq \Delta k_{3}$, the velocity variation of each mass was zero. Therefore, the initial conditions for the velocity of each mass were as follows: $\dot{y}_{1}=v \theta, \dot{y}_{2}=v \theta$, and $\dot{y}_{3}=v \theta$.

(2) Initial Conditions of Displacement. In the process of solving the vibration equation, initial displacement conditions of each mass were discussed according to the following conditions: the normal section was taken as the line, and the vehicle just passing over the pavement around the manhole was taken as the zero moment.

(a) When $H_{1} \leq \Delta k_{3}$, each mass deviates from the equilibrium position $H_{1}$. Thus, $y_{1}(0)=H_{1}$, $y_{2}(0)=H_{1}$, and $y_{3}(0)=H_{1}$.

(b) When $\Delta k \leq H_{1} \leq \Delta k_{2}+\Delta k_{3}$, spring $k_{3}$ had completely been restored, but masses $m_{1}$ and $m_{2}$ still deviate from equilibrium position $H_{1}$. Thus, $y_{1}(0)=H_{1}, y_{2}(0)=H_{1}$, and $y_{3}(0)=\Delta k_{3}$.

(c) When $\Delta k_{2}+\Delta k_{3} \leq H_{1} \leq \Delta k_{1}+\Delta k_{2}+\Delta k_{3}$, springs $k_{2}$ and $k_{3}$ have completely been restored, but mass $m_{1}$ still deviates from equilibrium position $H_{1}$. Thus, $y_{1}(0)=H_{1}, y_{2}(0)=\left(\Delta k_{2}+\Delta k_{3}\right)$, and $y_{3}(0)=\Delta k_{3}$. 
(d) When $\Delta k_{1}+\Delta k_{2}+\Delta k_{3} \leq H_{1}$, springs $k_{1}, k_{2}$, and $k_{3}$ have completely been restored, and mass $m_{1}$ fell freely, which was beyond the range of acceleration endurable by humans. So this situation was not discussed, and it also showed that the maximum height difference caused by damage could not exceed $\left(\Delta k_{1}+\Delta k_{2}+\Delta k_{3}\right)$.

2.2.2. Initial Conditions for Vehicles Passing over the Manhole Cover. When the vehicle was stationary on the manhole cover, the compressions of $k_{1}, k_{2}$, and $k_{3}$ were the same as those of the previous one. The compression of $k_{4}$ was $\Delta k_{4}=\left(m_{1}+m_{2}+m_{3}+m_{4}\right) g / k_{4}$.

(1) Initial Conditions of Velocity. When the vehicle enters the manhole cover area at time $t_{1}$, the height difference of the pavement caused by manhole cover subsidence is $\mathrm{H}_{2}$. Similar to the situation of the vehicle entering the pavement around the manhole which has been discussed, the initial conditions of the velocity of each mass when the vehicle enters the manhole cover area were as follows: $\dot{y}_{1}=\dot{y}_{1}\left(t_{1}\right), \dot{y}_{2}=\left(t_{1}\right)$, and $\dot{y}_{3}\left(t_{1}\right), \dot{y}_{4}=0$.

(2) Initial Conditions of Displacement. The initial displacement conditions of each mass were discussed according to the following conditions:

(a) When $H_{2} \leq \Delta k_{3}$, each mass deviates from the equilibrium position $H_{2}$. Thus, $y_{1}=y_{1}\left(t_{1}\right)+H_{2}$, $y_{2}=y_{2}\left(t_{1}\right)+H_{2}, y_{3}=y_{3}\left(t_{1}\right)+H_{2}$, and $y_{4}=0$.

(b) When $\Delta k_{3} \leq H_{2} \leq \Delta k_{2}+\Delta k_{3}$, spring $k_{3}$ had completely been restored, but masses $m_{1}$ and $m_{2}$ still deviate from equilibrium position $H_{2}$. Thus, $y_{1}=y_{1}\left(t_{1}\right)+H_{2}, \quad y_{2}=y_{2}\left(t_{1}\right)+H_{2}, \quad y_{3}=y_{3}\left(t_{1}\right)+$ $\Delta k_{3}$, and $y_{4}=0$.

(c) When $\Delta k_{2}+\Delta k_{3} \leq H_{2} \leq \Delta k_{1}+\Delta k_{2}+\Delta k_{3}$, springs $k_{2}$ and $k_{3}$ had completely been restored, but mass $m_{1}$ still deviates from equilibrium position $H_{2}$. Thus, $y_{1}=y_{1}\left(t_{1}\right)+H_{2}, y_{2}=y_{2}\left(t_{1}\right)+\Delta k_{2}+\Delta k_{3}, y_{3}=y_{3}$ $\left(t_{1}\right)+\Delta k_{3}$, and $y_{4}=0$.

(d) When $\Delta k_{1}+\Delta k_{2}+\Delta k_{3} \leq H_{2}$, this situation was also not discussed, and the maximum height difference $H_{2}$ could not exceed $\left(\Delta k_{1}+\Delta k_{2}+\Delta k_{3}\right)$.

When the vehicle leaves the manhole cover area or the pavement around the manhole area, the initial conditions could be discussed according to those of the vehicle passing over the manhole cover.

2.3. Evaluation Index and Standard for Driving Comfort. In ISO 2631-1-1997, weighted root mean square (RMS) of acceleration is used as the basic evaluation index for driving comfort [24], and the calculation method is shown in equation (3). Moreover, the relationships between driving comfort and weighted RMS of acceleration are listed in Table 2 .
TABLE 2: Relationships between driving comfort and RMS of weighted acceleration.

\begin{tabular}{lc}
\hline RMS of weighted acceleration $\left(\mathrm{m} / \mathrm{s}^{2}\right)$ & Driver's comfort \\
\hline$<0.315$ & Comfortable \\
$0.315 \sim 0.630$ & Slightly uncomfortable \\
$0.500 \sim 1.000$ & A little uncomfortable \\
$0.800 \sim 1.600$ & Uncomfortable \\
$1.250 \sim 2.500$ & Quite uncomfortable \\
$>2.000$ & Extremely uncomfortable \\
\hline
\end{tabular}

$$
a_{\omega}=\left[\frac{1}{T} \int_{0}^{T} a_{\omega}^{2}(t) \mathrm{d} t\right]^{0.5},
$$

where $a_{\omega}(t)$ is the weighted acceleration value at $t$ time $\left(\mathrm{m} / \mathrm{s}^{2}\right)$ and $T$ is the analysis time of vehicle vibration (s); 1 second was taken in actual analysis, and the timing began when the vehicle just entered the damaged area of pavement around the manhole. The frequency weight function is shown as follows:

$$
W(f)=\left\{\begin{array}{cc}
0.5, & 0.5<f<2, \\
\frac{f}{4}, & 2<f<4, \\
1, & 4<f<12.5, \\
\frac{12.5}{f}, & 12.5<f<80,
\end{array}\right.
$$

where $f$ is the frequency $(\mathrm{Hz})$.

Parts of the upper and lower limits for RMS of weighted acceleration overlap with other parts in Table 2. And the evaluation results of driving comfort were affected by the data overlap. At this time, a poor grade of comfort degree was taken due to the high requirement of driving comfort on a high-grade road. Because manholes are generally located in urban roads and require a high degree of driving comfort, the following analysis was defined according to "high standards." For example, when RMS of weighted acceleration was 0.9 , the evaluation of driver's comfort was "uncomfortable," rather than "a little uncomfortable."

\section{Evaluation of Driving Comfort and Analysis of Influencing Factors}

3.1. Analysis of Driver's Acceleration Variation. We assume the height differences caused by the pavement damage and the manhole cover were $H_{1}=1 \mathrm{~cm}$ and $H_{2}=1 \mathrm{~cm}$, respectively. We assume that the location of the pavement damage was $0.6 \mathrm{~m}$ away from the edge of the manhole cover, and the diameter of the manhole cover was $0.7 \mathrm{~m}$. Furthermore, the longitudinal slope value of the road was $4 \%$, the direction of the vehicle was downhill, and the speed of the vehicle was $36 \mathrm{~km} / \mathrm{h}$. As $\Delta k_{3}=\left(m_{1}+m_{2}+m_{3}\right)$ $\mathrm{g} / k_{3}=10.3 \mathrm{~cm}$, then the following relationship could be 
obtained: $H_{1} \leq \Delta k_{3}$ and $H_{2} \leq \Delta k_{3}$. Therefore, initial conditions for the vehicle entering the pavement around the manhole were as follows: $\dot{y}_{1}=0.4, \dot{y}_{2}=0.4, \dot{y}_{3}=0.4$, $y_{1}=0.01, y_{2}=0.01$, and $y_{3}=0.01$. And the initial conditions for the vehicle entering the manhole cover area after $0.06 \mathrm{~s}$ were as follows: $\dot{y}_{1}=\dot{y}_{1}\left(t_{1}\right), \quad \dot{y}_{2}=\dot{y}_{2}\left(t_{1}\right), \dot{y}_{3}=\dot{y}_{3}\left(t_{1}\right)$, $\dot{y}_{4}=0, y_{1}=y_{1}\left(t_{1}\right)+0.01, y_{2}=y_{2}\left(t_{1}\right)+0.01, \quad y_{3}=y_{3}\left(t_{1}\right)$ +0.01 , and $y_{4}=0$. Equations (1) and (2) were solved according to those initial conditions and combined with MATLAB programming, and the development law of driver acceleration with time was obtained, as shown in Figure 2.

There were three mutation points of driver acceleration due to the obvious change in road roughness and the new "excitation" of vehicle vibration.

The corresponding time of mutation point 1 was $0.06 \mathrm{~s}$, when the vehicle entered the manhole cover area from the damaged pavement around the manhole area. And the acceleration increased from $1.5 \mathrm{~m} / \mathrm{s}^{2}$ to $3.3 \mathrm{~m} / \mathrm{s}^{2}$ instantaneously. The corresponding time of mutation point 2 was $0.13 \mathrm{~s}$, when the vehicle left the manhole cover and entered the damaged pavement around the manhole area on the other side. And the acceleration decreased from $3.6 \mathrm{~m} / \mathrm{s}^{2}$ to $1.1 \mathrm{~m} / \mathrm{s}^{2}$ instantaneously. The corresponding time of mutation point 3 was $0.19 \mathrm{~s}$. The vehicle drove into the normal section from the damaged pavement around the manhole section. At this time, the acceleration increased from $0.3 \mathrm{~m} / \mathrm{s}^{2}$ to $2.9 \mathrm{~m} / \mathrm{s}^{2}$ suddenly.

Driver's acceleration reached the maximum value of $3.6 \mathrm{~m} / \mathrm{s}^{2}$ at $0.12 \mathrm{~s}$ when the vehicle was driving over the manhole cover. According to equations (3) and (4), RMS value of weighted acceleration was calculated, and it was $0.975 \mathrm{~m} / \mathrm{s}^{2}$. And the comfort degree was evaluated as "uncomfortable" according to Table 2. The surface roughness had an obvious influence on driver acceleration.

3.2. Analysis of Influencing Factors. There are many factors that affect a driver's comfort when driving on the road, including driver's driving intelligence, vehicle vibration characteristics, and road condition (comprising road roughness, road alignment, and cultural landscape) [25]. Thus, 9 main factors were discussed on the effect of acceleration combined with existing research results [23], such as vehicle speed, height difference caused by damage to the pavement around the manhole, manhole cover subsidence and stiffness, tire stiffness and damping, and longitudinal slope value. Then, the acceleration-time curves were calculated, as shown in Figure 3. Also, the evaluation results of driving comfort are listed in Table 3.

The following conclusions can be drawn by analyzing Figure 3 and Table 3.

(1) Figure 3(a) shows that the maximum acceleration of the driver of $3.3 \mathrm{~m} / \mathrm{s}^{2}$ ignored the manhole cover vibration, which is $8.3 \%$ less than that of considering the manhole cover vibration. Table 3 shows that the RMS weighted acceleration of the driver was $0.975 \mathrm{~m} / \mathrm{s}^{2}$ and $0.830 \mathrm{~m} / \mathrm{s}^{2}$, respectively, when considering manhole cover vibration or not. The driving

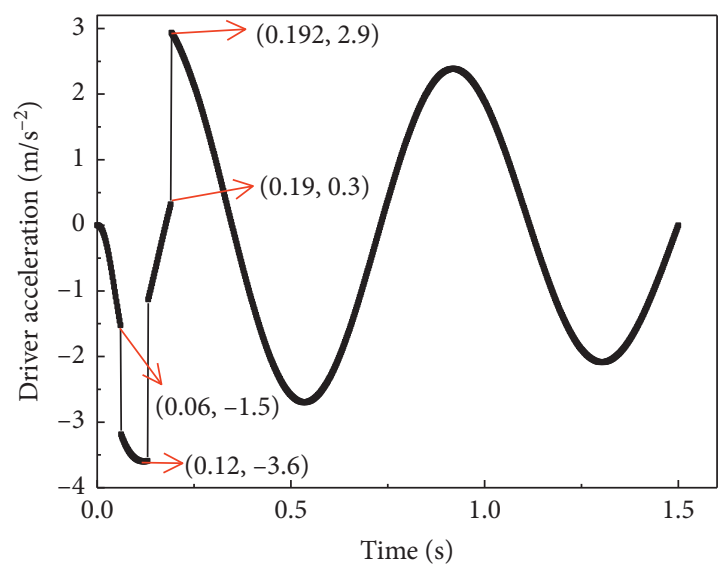

Figure 2: Development law of driver acceleration with time.

comfort degree was defined as "uncomfortable" according to Table 2. The results indicate that the vibration of the manhole cover had a little effect on driving comfort.

(2) As shown in Figure 3(b), the maximum acceleration of the driver decreased gradually with increasing stiffness of the manhole cover. As the stiffness of the manhole cover increased from $10^{4} \mathrm{~N} / \mathrm{m}$ to $10^{7} \mathrm{~N} / \mathrm{m}$, the maximum acceleration of the driver decreased from $4.5 \mathrm{~m} / \mathrm{s}^{2}$ to $3.6 \mathrm{~m} / \mathrm{s}^{2}$, a decrease of $25.0 \%$. As the stiffness of the manhole cover increased from $10^{2} \mathrm{~N} / \mathrm{m}$ to $10^{7} \mathrm{~N} / \mathrm{m}$, the RMS value of weighted acceleration decreased gradually, and the comfort degree changed from "quite uncomfortable" to "uncomfortable." However, the comfort degree had a little variation, while the stiffness of the manhole cover continued to increase. It could be seen that the stiffness coefficient of the manhole cover had a certain influence on driving comfort, but the influence range was limited.

(3) As the subsidence of the manhole increased from $1 \mathrm{~cm}$ to $3 \mathrm{~cm}$ and $6 \mathrm{~cm}$, the maximum acceleration of the driver changed to $4.7 \mathrm{~m} / \mathrm{s}^{2}$ and $6.6 \mathrm{~m} / \mathrm{s}^{2}$, an increase of $30.6 \%$ and $91.7 \%$, respectively, as shown in Figure 3(c). As the subsidence of the manhole increased, the driving comfort degree decreased gradually, as we can see in Table 3. And when the subsidence of the manhole increased to $4 \mathrm{~cm}$, the comfort degree changed from "uncomfortable" to "quite uncomfortable." Thus, the subsidence of the manhole had a great influence on driving comfort.

(4) Figure 3(d) shows that with increased driving speed from $36 \mathrm{~km} / \mathrm{s}$ to $60 \mathrm{~km} / \mathrm{s}$ and $80 \mathrm{~km} / \mathrm{s}$, the maximum acceleration of the driver changed to $5.1 \mathrm{~m} / \mathrm{s}^{2}$ and $6.6 \mathrm{~m} / \mathrm{s}^{2}$, an increase of $41.7 \%$ and $91.7 \%$, respectively. Table 4 shows that comfort of driver decreased gradually with increasing driving speed. As driving speed changed from $40 \mathrm{~km} / \mathrm{s}$ to $50 \mathrm{~km} / \mathrm{s}$ and $80 \mathrm{~km} / \mathrm{s}$, the comfort degree changed from "uncomfortable" to "quite uncomfortable" and "extremely uncomfortable," respectively. Thus, speed had a distinct impact on driving comfort. 


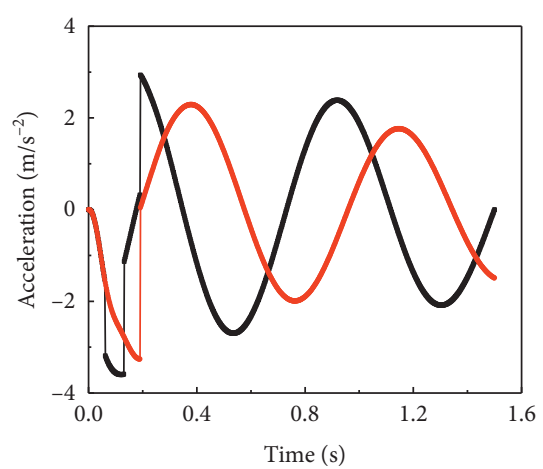

$\rightarrow$ Considering vibration of manhole cover - Ignoring vibration of manhole cover

(a)

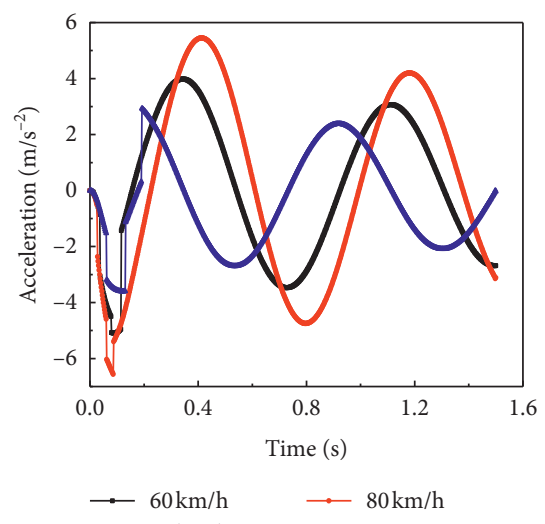

(d)

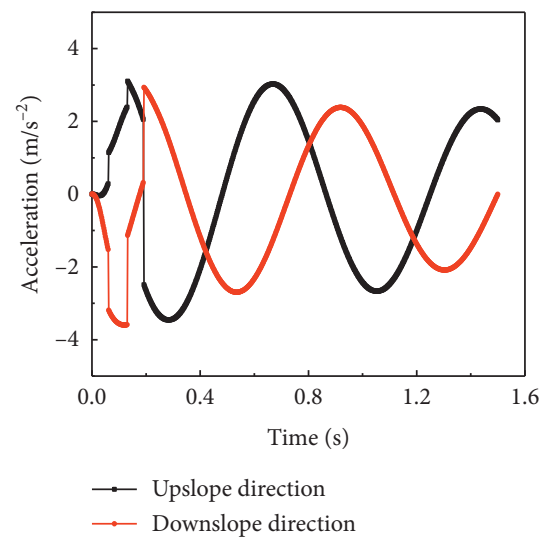

(g)

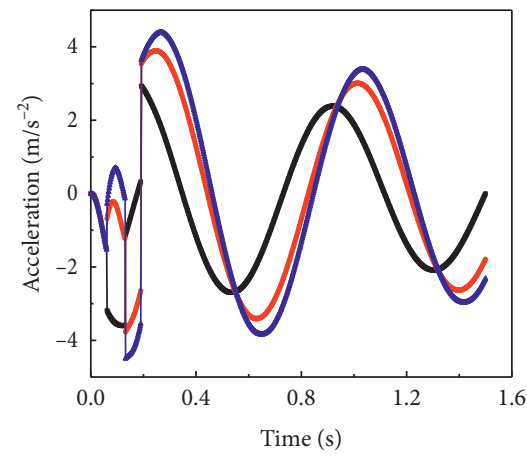

$\because 1 \times 10^{7} \mathrm{~N} / \mathrm{m} \quad \longrightarrow 1 \times 10^{5} \mathrm{~N} / \mathrm{m}$

(b)

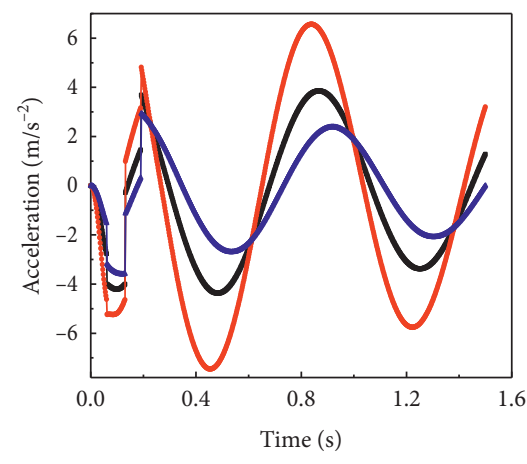

$\rightarrow 3 \mathrm{~cm}$

$\longrightarrow 6 \mathrm{~cm}$

(e)

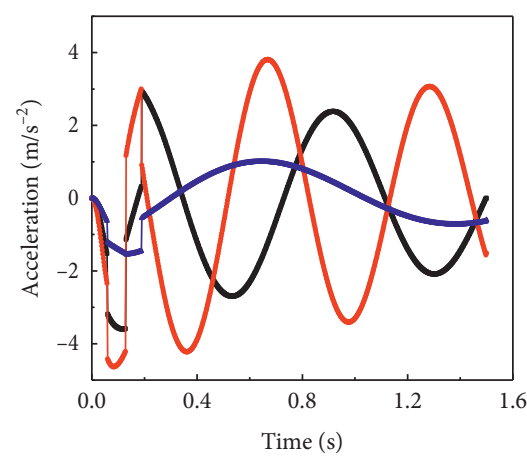

$\longrightarrow 4.8 \times 10^{5} \mathrm{~N} / \mathrm{m} \longrightarrow 1 \times 10^{6} \mathrm{~N} / \mathrm{m}$

(h)

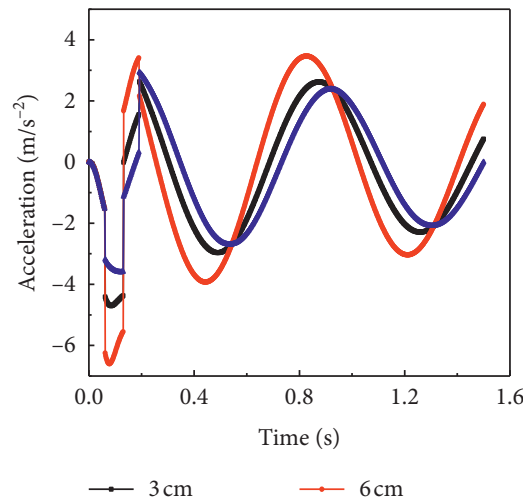

(c)

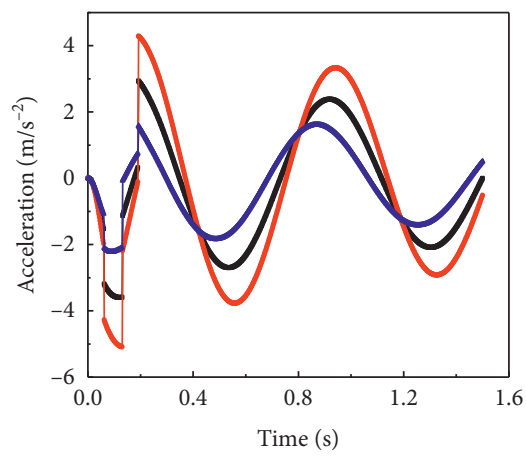

$-4 \%$
$-\quad 2 \%$

$\longrightarrow 6 \%$

(f)

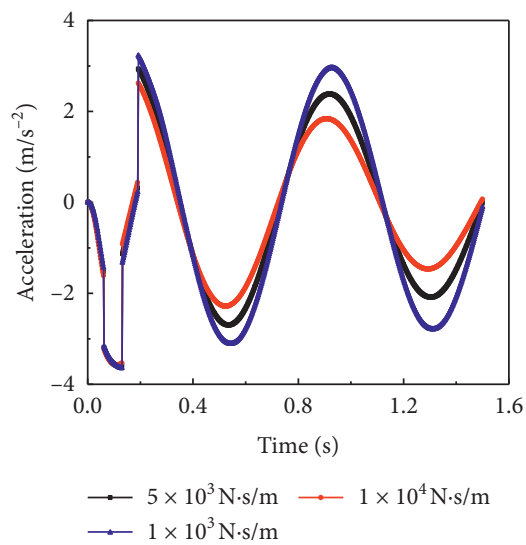

(i)

Figure 3: Driver acceleration changes with time under the influence of different factors. (a) Vibration of the manhole cover. (b) Stiffness of the manhole cover. (c) Subsidence of manhole. (d) Driving speed. (e) Height difference. (f) Longitudinal slope value. (g) Driving direction. (h) Tire stiffness coefficient. (i) Tire damping coefficient.

(5) Figure 3(e) and Table 3 show that driver's maximum acceleration increased and the driver's driving comfort decreased gradually as height difference caused by damage to the pavement around the manhole increased. As the height difference increased from $1 \mathrm{~cm}$ to $3 \mathrm{~cm}$ and $6 \mathrm{~cm}$, the driver's maximum acceleration was $4.4 \mathrm{~m} / \mathrm{s}^{2}$ and $7.5 \mathrm{~m} / \mathrm{s}^{2}$, an increase of $25.0 \%$ and $108.3 \%$, respectively. Furthermore, when the height difference increased from $2 \mathrm{~cm}$ to $3 \mathrm{~cm}$ and $5 \mathrm{~cm}$, the comfort degree changed from "uncomfortable" to "quite uncomfortable" and "extremely uncomfortable," respectively. Hence, the height difference caused by damage to the pavement around the manhole had a conspicuous effect on driving comfort. As we can see by comparing Figures 3(c) and 3(e), the subsidence value had a greater effect on the early stage $(0.06 \mathrm{~s} \sim 0.13 \mathrm{~s})$ of vehicle vibration, while height difference caused by damage to the pavement around the 
TABLE 3: Influencing factors and evaluation of driving comfort.

\begin{tabular}{|c|c|c|c|}
\hline Influencing factors & & $a_{w}\left(\mathrm{~m} / \mathrm{s}^{2}\right)$ & Driving comfort degree \\
\hline \multirow{8}{*}{ Driving speed $(\mathrm{km} / \mathrm{h})$} & 10 & 0.533 & A little uncomfortable \\
\hline & 20 & 0.663 & A little uncomfortable \\
\hline & 30 & 0.849 & Uncomfortable \\
\hline & 40 & 1.063 & Uncomfortable \\
\hline & 50 & 1.291 & Quite uncomfortable \\
\hline & 60 & 1.526 & Quite uncomfortable \\
\hline & 70 & 1.766 & Quite uncomfortable \\
\hline & 80 & 2.009 & Extremely uncomfortable \\
\hline \multirow{8}{*}{ Longitudinal slope value (\%) } & 1 & 0.525 & A little uncomfortable \\
\hline & 2 & 0.631 & A little uncomfortable \\
\hline & 3 & 0.790 & A little uncomfortable \\
\hline & 4 & 0.975 & Uncomfortable \\
\hline & 5 & 1.176 & Uncomfortable \\
\hline & 6 & 1.384 & Quite uncomfortable \\
\hline & 7 & 1.598 & Quite uncomfortable \\
\hline & 8 & 1.814 & Quite uncomfortable \\
\hline \multirow{8}{*}{ Tire damping coefficient $\left(10^{4} \mathrm{~N} \cdot \mathrm{s} / \mathrm{m}\right)$} & 0.1 & 1.106 & Uncomfortable \\
\hline & 0.5 & 0.975 & Uncomfortable \\
\hline & 1 & 0.851 & Uncomfortable \\
\hline & 2 & 0.692 & A little uncomfortable \\
\hline & 8 & 0.545 & A little uncomfortable \\
\hline & 20 & 0.638 & A little uncomfortable \\
\hline & 40 & 0.754 & A little uncomfortable \\
\hline & 100 & 0.911 & Uncomfortable \\
\hline \multirow{8}{*}{ Manhole cover stiffness coefficient $(\mathrm{N} / \mathrm{m})$} & $10^{2}$ & 1.423 & Quite uncomfortable \\
\hline & $10^{3}$ & 1.420 & Quite uncomfortable \\
\hline & $10^{4}$ & 1.395 & Quite uncomfortable \\
\hline & $10^{5}$ & 1.220 & Uncomfortable \\
\hline & $10^{6}$ & 0.977 & Uncomfortable \\
\hline & $10^{7}$ & 0.975 & Uncomfortable \\
\hline & $10^{8}$ & 0.979 & Uncomfortable \\
\hline & $10^{9}$ & 0.979 & Uncomfortable \\
\hline \multirow{8}{*}{$\begin{array}{l}\text { Height difference caused by damage to pavement } \\
\text { around manhole }(\mathrm{cm})\end{array}$} & 0.5 & 0.901 & Uncomfortable \\
\hline & 1 & 0.975 & Uncomfortable \\
\hline & 2 & 1.184 & Uncomfortable \\
\hline & 3 & 1.443 & Quite uncomfortable \\
\hline & 4 & 1.730 & Quite uncomfortable \\
\hline & 5 & 2.033 & Extremely uncomfortable \\
\hline & 6 & 2.346 & Extremely uncomfortable \\
\hline & 8 & 2.989 & Extremely uncomfortable \\
\hline \multirow{8}{*}{ Subsidence of manhole $(\mathrm{cm})$} & 0.5 & 0.968 & Uncomfortable \\
\hline & 1 & 0.975 & Uncomfortable \\
\hline & 2 & 1.019 & Uncomfortable \\
\hline & 3 & 1.095 & Uncomfortable \\
\hline & 4 & 1.198 & Uncomfortable \\
\hline & 6 & 1.461 & Quite uncomfortable \\
\hline & 8 & 1.769 & Quite uncomfortable \\
\hline & 10 & 2.104 & Extremely uncomfortable \\
\hline \multirow{8}{*}{ Tire stiffness coefficient $\left(10^{5} \mathrm{~N} / \mathrm{m}\right)$} & 1 & 0.405 & Slightly uncomfortable \\
\hline & 2 & 0.623 & A little uncomfortable \\
\hline & 4 & 0.871 & Uncomfortable \\
\hline & 8 & 1.227 & Uncomfortable \\
\hline & 16 & 1.650 & Quite uncomfortable \\
\hline & 32 & 1.780 & Quite uncomfortable \\
\hline & 64 & 1.706 & Quite uncomfortable \\
\hline & 128 & 1.622 & Quite uncomfortable \\
\hline \multirow{2}{*}{ Considering Vibration of manhole cover or not } & Yes & 0.975 & Uncomfortable \\
\hline & No & 0.830 & Uncomfortable \\
\hline \multirow{2}{*}{ Diving direction } & Uphill & 1.099 & Uncomfortable \\
\hline & Downhill & 0.975 & Uncomfortable \\
\hline
\end{tabular}


manhole had a greater impact on the middle and late stages (after $0.3 \mathrm{~s}$ ) of vehicle vibration.

(6) As the longitudinal slope value changed from $4 \%$ to $2 \%$ and $6 \%$, the maximum acceleration became $2.2 \mathrm{~m} / \mathrm{s}^{2}$ and $5.1 \mathrm{~m} / \mathrm{s}^{2}$, a decrease of $38.9 \%$ and an increase of $52.8 \%$, respectively, as shown in Figure 3(f). As the longitudinal slope increased from $3 \%$ to $4 \%$ and $6 \%$, the comfort degree changed from "a little uncomfortable" to "uncomfortable" and "quite uncomfortable." Therefore, driving comfort was significantly affected by the longitudinal slope.

(7) Figure 3(g) shows that the maximum driver acceleration was $3.5 \mathrm{~m} / \mathrm{s}^{2}$ and $3.6 \mathrm{~m} / \mathrm{s}^{2}$ and RMS weighted acceleration was 1.099 and 0.975 , respectively, while the vehicle was moving uphill and downhill, respectively. At the same time, comfort degrees were both "uncomfortable." Thus, the vehicle driving direction had little effect on the driving comfort but moving uphill or downhill affected speed which had a significant effect on driving comfort.

(8) With the increase of tire stiffness, vehicle vibration periods decreased, and frequency increased gradually, which was detrimental to driving safety and comfort, as shown in Figure 3(h). When the stiffness coefficient increased from $1 \times 10^{5} \mathrm{~N} / \mathrm{m}$ to $4.8 \times 10^{5} \mathrm{~N} / \mathrm{m}$ and $1 \times 10^{6} \mathrm{~N} / \mathrm{m}$, the maximum acceleration increased from $1.5 \mathrm{~m} / \mathrm{s}^{2}$ to $3.6 \mathrm{~m} / \mathrm{s}^{2}$ and $4.6 \mathrm{~m} / \mathrm{s}^{2}$, an increase of $140.0 \%$ and $206.7 \%$, respectively. Table 3 shows that with the increase of tire stiffness, RMS weighted acceleration increased first and then decreased. Thus, tire stiffness coefficient had an obvious impact on driving comfort.

(9) Figure 3(i) shows that maximum acceleration changed little as tire damping increased. However, attenuation of vehicle vibration was accelerated, which is beneficial to vehicle driving comfort. Table 3 shows that with the increase of tire damping, the RMS weighted acceleration value decreased first and then increased but had little variation. And the driving comfort degrees were "a little uncomfortable" and "uncomfortable," respectively. Thus, tire damping had little effect on driving comfort.

It was found that driving speed, height difference caused by damage of the pavement around the manhole, longitudinal slope, subsidence of the manhole cover, tire damping and stiffness, and manhole cover stiffness all had a significant effect on driving comfort. However, the driving direction could be ignored for it had little effect on driving comfort.

While many factors had great influence on driving comfort, a further study needed to be done to identify which ones play the most significant role. The grey correlation entropy method was used to point out the main control factors of driving comfort.

\section{Analysis of the Influencing Factors Based on Grey Correlation Entropy Method}

4.1. Grey Correlation Entropy Method. Grey correlation refers to the uncertain relationship between different things. It is a systematic analysis method used to measure the degree of correlation between factors and systems to compare the influence degree between factors. However, this method can easily generate the problem that the local point correlation value controls the overall point correlation value, causing loss. To solve this problem, the grey correlation entropy method was proposed [26].

For grey correlation entropy analysis, let $X$ be the grey correlation factor set. Take $J$ as the reference set $\left(X_{0}=\left\{X_{0}(k) \mid, k=1,2, \ldots, n\right\}\right)$, and take 7 influencing factors (except "driving direction" and "considering the vibration of manhole cover or not" in Table 3$)$ as the comparison set $\left(X_{i}=\left\{X_{i}(k) \mid, k=1,2, \ldots, n\right\}\right)(i=1,2, \ldots, 7)$. In the calculation process, the magnitude and unit of each factor were different. Therefore, in order to eliminate influence on the calculation result, the data need to be processed to obtain the dimensionless set $X_{i}$ and the reference set $X_{0}$, which was $X_{i}^{\prime}\left\{X_{i}(k) / \bar{X}_{i} \mid, k=1,2, \ldots, n\right\}(i=0,1,2, \ldots, 7)$.

The process of grey correlation entropy analysis is summarized into the following 5 steps:

Step 1. The grey correlation coefficient of $X_{i}$ to $X_{0}$ was obtained from the following equation:

$$
\begin{gathered}
\xi\left[x_{0}(k), x_{i}(k)\right]= \\
\frac{\min _{i=1, m} \min _{k=1, n}\left|x_{0}(k)-x_{i}(k)\right|+\rho \max _{i=1, m} \max _{k=1, n}\left|x_{0}(k)-x_{i}(k)\right|}{\left|x_{0}(k)-x_{i}(k)\right|+\rho \max _{i=1, m} \max _{k=1, n}\left|x_{0}(k)-x_{i}(k)\right|},
\end{gathered}
$$

where $\xi$ is the grey correlation coefficient and $\rho$ is the resolution coefficient ( $\rho \in[0,1]$, and is 0.5 generally).

Step 2. The distribution density of grey correlation entropy was obtained according to equation (6).

Let $R_{i}=\left\{\xi\left[x_{0}(k), x_{i}(k)\right]\right\}$, and the defined distribution density of grey correlation entropy as follows:

$$
P_{h} \triangleq \frac{\xi\left[x_{0}(h), x_{i}(h)\right]}{\sum_{k=1}^{n} \xi\left[x_{0}(h), x_{i}(h)\right]},
$$

where $P_{h} \in P_{i}(h=1,2 \ldots, n)$ and $P_{h} \geq 0, \sum P_{h}=1$.

Step 3. The grey correlation entropy was obtained from equations (7) and (8).

Let $X=\left(x_{1}, x_{2}, \ldots, x_{n}\right), \forall, x_{i} \geq 0, \sum x_{i}=1$, and grey correlation entropy as follows:

$$
H \otimes(x) \triangleq-\sum_{i=1}^{n} x_{i} \ln x_{i},
$$

where $x_{i}$ is the attribute information.

The grey correlation entropy of $X_{i}$ is

$$
H\left(R_{i}\right) \triangleq-\sum_{h=1}^{n} P_{h} \ln P_{h} .
$$

Step 4. The grey entropy correlation degree of $X_{i}$ was obtained from the following equation: 
TABLE 4: Computed results and ordered correlation values of grey entropy.

\begin{tabular}{lccc}
\hline Factors & Grey correlation entropy & Grey entropy correlation degree & Ordered \\
\hline Driving speed & 3.9511324 & 0.9999718 & 2 \\
Height difference & 3.9507091 & 0.9998647 & 3 \\
Longitudinal slope & 3.9511341 & 0.9999723 & 1 \\
Tire damping coefficient & 3.9449697 & 0.9984121 & 7 \\
Tire stiffness coefficient & 3.9483077 & 0.9992570 & 5 \\
Subsidence of manhole & 3.9501511 & 0.9997235 & 4 \\
Manhole cover stiffness coefficient & 3.9453712 & 0.9985138 & 6 \\
\hline
\end{tabular}

$$
E\left(X_{i}\right) \triangleq \frac{H\left(R_{i}\right)}{H_{\max }},
$$

where $H_{\max }=\ln n$ is the maximum value of the grey entropy and represents the maximum value of the difference information column composed of $n$ elements.

Step 5. Significance of influencing factors was determined by the grey entropy correlation degree.

4.2. Results. Grey correlation entropy analysis for the 7 factors shown in Table 4 was performed, and the computed results and ordered correlation values of grey entropy are shown in Table 4.

From Table 4, it can be seen that the significance order of the different factors that affected driving comfort was as follows: longitudinal slope, driving speed, height difference, subsidence of manhole, tire stiffness coefficient, manhole cover stiffness coefficient, and tire damping coefficient. Driving speed, height difference caused by damage to the pavement around the manhole, longitudinal slope, and subsidence of manhole were the four most important factors which affected driving comfort. Height difference and subsidence of manhole were both irregularity problems. However, influence of the height difference on driving comfort was greater than that of manhole cover subsidence. When the road surface roughness was poor, the existence of the manhole cover with elastic characteristics could reduce driving discomfort when passing over an irregular road.

\section{Conclusions}

(1) Under the same basic parameters, when the vehicle passed over the manhole cover, the driver's acceleration reached the maximum of $3.6 \mathrm{~m} / \mathrm{s}^{2}$, the RMS weighted acceleration was $0.975 \mathrm{~m} / \mathrm{s}^{2}$, and the driving comfort degree was evaluated as "uncomfortable." The existence of the manhole cover and damage to the pavement around the manhole greatly reduced the driving comfort.

(2) Driving speed, height difference, longitudinal slope, subsidence of the manhole cover, tire damping and stiffness, and manhole cover stiffness all had significant influence on the driving comfort, and all of them should be paid more attention. Meanwhile, driving direction had little effect on driving comfort, which could be ignored.

(3) Grey correlation entropy analysis showed that the order of significant influencing factors on driving comfort was longitudinal slope, driving speed, height difference, subsidence of inspection wells, tire stiffness, cover stiffness, and tire damping. Driving speed, height difference caused by damage to the pavement around the manhole, longitudinal slope, and subsidence of the manhole cover were the four most important factors which affected driving comfort.

(4) The effect of height difference on driving comfort was greater than that of manhole cover subsidence. Thus, the existence of a manhole cover with elastic characteristics could reduce driving discomfort in poor roughness conditions.

\section{Data Availability}

The data used to support the findings of this study are available from the corresponding author upon request.

\section{Conflicts of Interest}

The authors declare no conflicts of interest.

\section{Acknowledgments}

This research was supported by the Shandong Provincial Natural Science Foundation (project ZR2018BEE039), Key Research and Development Program of Shandong Province (project 2019GSF109067), and funds from Doctoral Research Foundation of Shandong Jianzhu University (no. XNBS1844). The author gratefully acknowledges the financial support.

\section{References}

[1] Y. Liu, H. Wang, S. L. Tighe, G. Zhao, and Z. You, "Effects of preheating conditions on performance and workability of hot in-place recycled asphalt mixtures," Construction and Building Materials, vol. 226, pp. 288-298, 2019.

[2] J. Zhou, Settlement Law and Improvement Measures of the Manhole on the Roadway, Master's thesis, Chongqing University, Chongqing, China, 2013.

[3] Z. W. Chen, S. Xu, H. L. Zhang, and G. Zhang, "Mechanistic method of predicting asphalt pavement roughness using real pavement profile and complete vehicle model," Journal of 
Chang'an University (Natural Science Edition), vol. 38, pp. 58-66, 2018.

[4] Y. J. Jin, X. S. Yin, and L. G. Xiao, "Application and research of high performance polymer concrete in covers," in Proceedings of the 2011 International Conference on Electrical and Control Engineering, pp. 3366-3369, Yichang, China, September 2011.

[5] M. Q. He and L. Y. Wei, "Mechanical analysis of urban road inspection shift," Journal of Hebei University of Technology, vol. 3, pp. 109-112, 2014.

[6] A. Topal and B. Sengoz, "Determination of fine aggregate angularity in relation with the resistance to rutting of hot-mix asphalt," Construction and Building Materials, vol. 19, no. 2, pp. 155-163, 2005.

[7] J.-R. Chang, S.-R. Yang, and K.-H. Lin, "Performance of new resin cement in rapid manhole vertical adjustment," Materials Research Innovations, vol. 18, no. 2, pp. 857-862, 2014.

[8] Z. Q. Zhang, C. Xu, G. L. Cheng, and L. Song, "Pavement performance of cold patch asphalt liquid," Journal of Jiangsu University (Nature Science), vol. 38, pp. 236-242, 2017.

[9] J. Gao, H. Wang, J. Chen, X. Meng, and Z. You, "Laboratory evaluation on comprehensive performance of polyurethane rubber particle mixture," Construction and Building Materials, vol. 224, pp. 29-39, 2019.

[10] Q. M. Zhao, H. L. Zhang, J. P. Gao, and G. Guo, "Study on maintenance standard of CRCP in punch-out area based on roughness," Journal of Highway and Transportation Research and Development, vol. 32, pp. 130-135, 2015.

[11] Q. M. Zhao, H. L. Zhang, and W. Jia, "Study of contact force between vehicle and road and influence factors in punch-out area," Journal of Hefei University of Technology (Natural Science), vol. 38, pp. 300-304, 2015.

[12] X. Shao, F. Naghdy, H. Du, and Y. Qin, "Coupling effect between road excitation and an in-wheel switched reluctance motor on vehicle ride comfort and active suspension control," Journal of Sound and Vibration, vol. 443, pp. 683-702, 2019.

[13] H. Zeng, H. Park, and B. Smith, "Impact of vehicle dynamic systems on a connected vehicle-enabled pavement roughness estimation," Journal of Infrastructure Systems, vol. 25, no. 1, Article ID 04018046, 2019.

[14] S. Li, S. Yang, and L. Chen, "A nonlinear vehicle-road coupled model for dynamics research," Journal of Computational and Nonlinear Dynamics, vol. 8, pp. 101-114, 2013.

[15] B. Zhang, Dynamic Analysis and Comfort Evaluation of the Vehicle-Road Coupled Vibration System, Central South University, Changsha, China, 2013.

[16] S. Li and S. Yang, "Investigation on dynamics of a threedirectional coupled vehicle-road system," Journal of Vibroengineering, vol. 17, pp. 125-136, 2015.

[17] Y. Lu, S. Yang, and S. Li, "Research on dynamics of a class of heavy vehicle-tire-road coupling system," Science China Technological Sciences, vol. 54, no. 8, pp. 2054-2063, 2011.

[18] J. M. Ling, S. F. Liu, J. Yuan, and W. Yang, "Applicability of IRI based evaluation of airport pavement roughness," Journal of Traffic and Transportation Engineering, vol. 17, pp. 20-27, 2017.

[19] Q. Li and J. Q. Liu, “Asphalt pavement evenness deterioration analysis based on the vehicle-pavement interaction," Journal of Vibration and Shock, vol. 37, pp. 76-81+116, 2018.

[20] J. M. Ling, S. F. Liu, J. Yuan, and X. Lei, "Comprehensive analysis of pavement roughness for airport and road with different roughness excitation," Journal of Tongji University (Nature Science), vol. 45, pp. 519-526, 2017.
[21] Y. F. Song and R. F. Chen, "Analysis method of vehicle response caused by pavement roughness," Journal of Traffic and Transportation Engineering, vol. 4, pp. 39-43, 2007.

[22] H. L. Zhang and W. Q. Yang, "Evaluation method of pavement roughness based on 5-DOF human-vehicle-road vibration model," Journal of Traffic and Transportation Engineering, vol. 10, pp. 16-22, 2010.

[23] W. Q. Yang, Research on Asphalt Pavement Evaluation Method Based on Human-Vehicle-Road Interaction, Chang'an University, Xi'an, China, 2009.

[24] ISO 2631-1-1997, Mechanical Vibration and Shock-Evaluation of Human Exposure to Whole- Body Vibration Part 1: General Requirement, ISO 2631-1-1997, Geneva, Switzerland, 1997.

[25] Q. M. Zhao, Study on Mechanism and Prediction of the Distress of Punch Out in Continuously Reinforced Concrete Pavement Based on Two Scale Model, Chang'an University, Xi'an, China, 2015.

[26] P. H. Zhao, Study on the Effects of Formation and Stability for Emulsified Asphalt, China University of Petroleum, Qingdao, East China, 2013. 


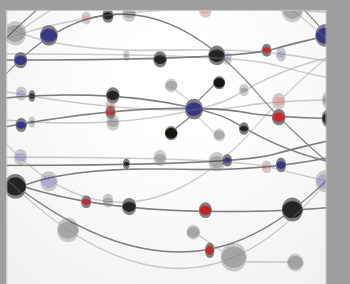

The Scientific World Journal
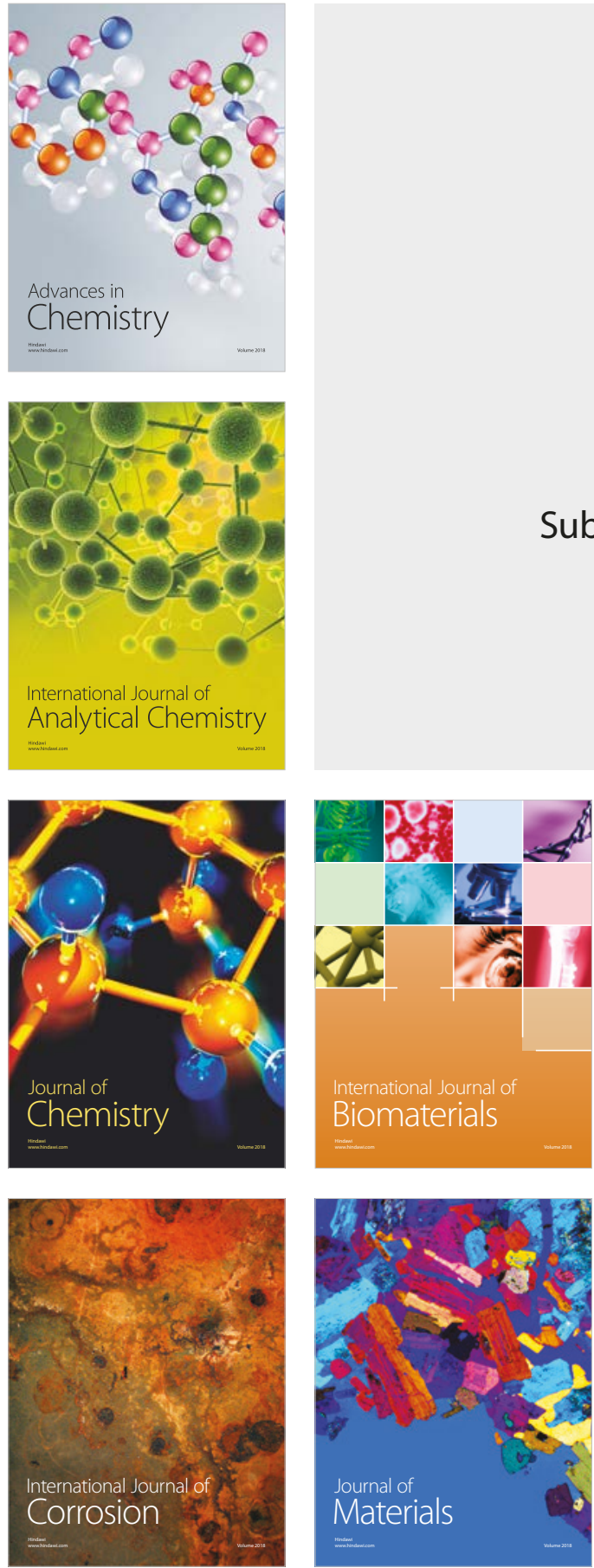

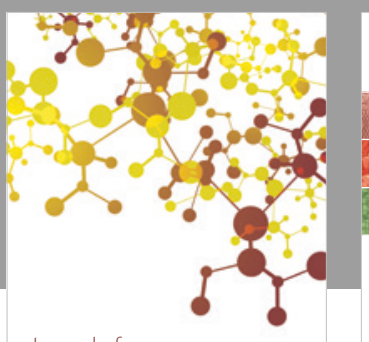

Journal of

Applied Chemistry
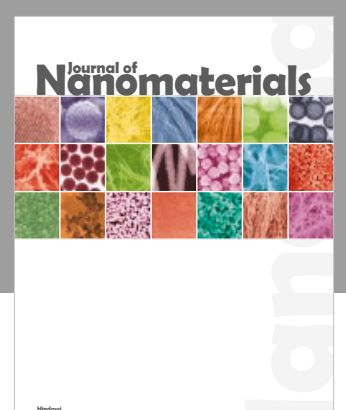

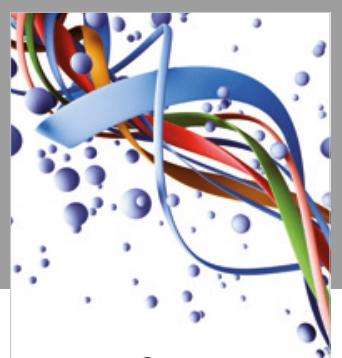

Scientifica

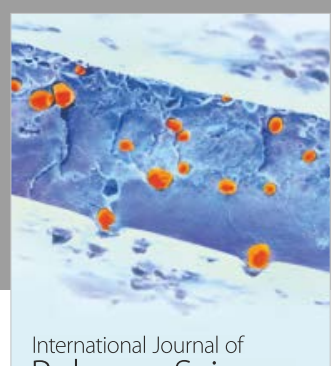

Polymer Science

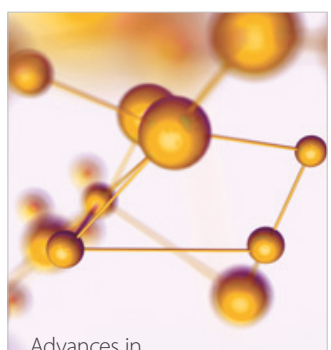

Physical Chemistry
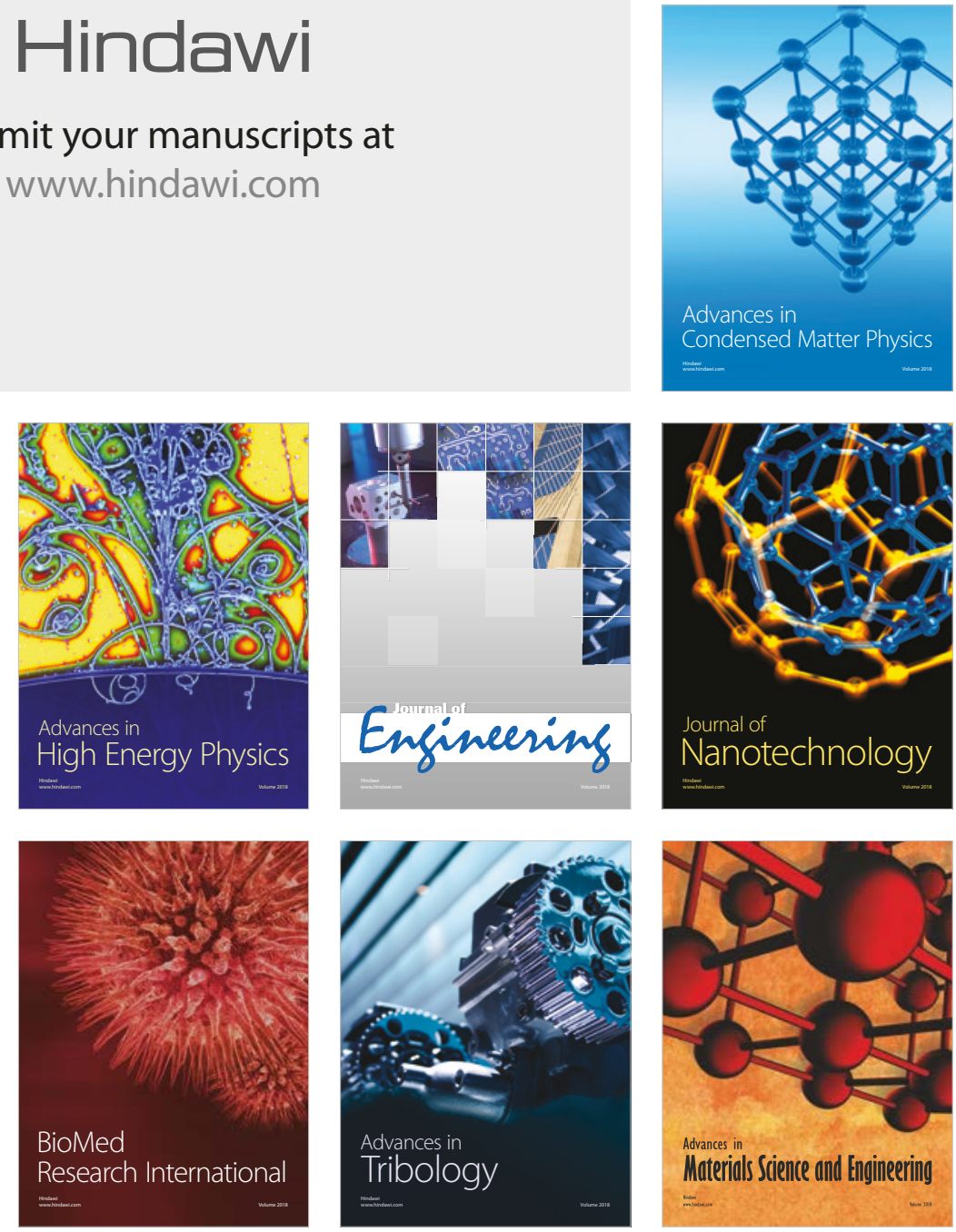